\title{
ANALISIS PENGARUH SERVICE QUALITY DAN CORPORATE IMAGE TERHADAP CUSTOMER SATISFACTION SERTA IMPLIKASINYA TERHADAP CUSTOMER LOYALTY PADA KONSUMEN RESTORAN MERADELIMA DI JAKARTA SELATAN
}

\author{
Senja Dara Fika Saputri \\ Program Studi Magister Manajemen Universitas Tarumanagara \\ senjafika@gmail.com
}

Masuk : 07-12-2019, revisi : 07-01-2020 diterima untuk diterbitkan : 07-01-2020

\begin{abstract}
This study aims to determine whether or not the influence of service quality, corporate image and customer satisfaction on purchasing decisions at Meradelim Restaurant. Brand image and brand trust are factors that can influence consumer purchasing decisions. A good service quality will have a positive impact on the company which will ultimately benefit the company through increased consumer purchases of products or services. This study uses a sample and a population of 110 respondents who are cutomer at Meradelima Restaurant, using purposive sampling method. The results showed that service quality, corporate image and customer satisfaction had a positive and significant effect on purchasing decisions.
\end{abstract}

Abstrak : Penelitian ini bertujuan untuk mengetahui ada atau tidaknya pengaruh service quality, corporate image dan customer satisfaction terhadap keputusan pembelian di Restoran Meradelima. Service quality, corporate image dan customer satisfaction merupakan faktor yang dapat mempengaruhi keputusan pembelian pada konsumen. service quality, yang baik akan memberikan dampak positif bagi perusahaan yang akhirnya akan memberikan keuntungan bagi perusahaan melalui peningkatan pembelian pada konsumen terhadap produk atau jasa. Penelitian ini menggunakan sampel dan populasi sebanyak 110 responden konsumen di Meradelima Restoran, menggunakan metode purposive sampling. Hasil penelitian menunjukan bahwa service quality, corporate image dan customer satisfaction berpengaruh positif dan signifikan terhadap keputusan pembelian.

Kata Kunci : Service Quality, Corporate Image, Customer Satisfaction, Keputusan Pembelian

\section{PENDAHULUAN}

Pertumbuhan penduduk di Indonesia menunjukkan angka yang cukup tinggi dari tahun ke tahun. Dengan meningkatnya jumlah penduduk maka kebutuhan masyarakat akan meningkat pula mulai dari bidang ekonomi, sosial, dan pemerintahan. Semakin meningkatnya jumlah penduduk dari tahun ke tahun, hal ini tentu akan berpengaruh terhadap peluang pasar industri restoran di wilayah Jakarta Selatan.

Citra merek suatu perusahaan membantu konsumen dalam mengenali kebutuhan mereka dan membedakan merek dari pesaing yang bertujuan untuk memotivasi pelanggan untuk membeli merek (Hsieh, Pan, \& Setiono, 2004).

Salah satu strategi perusahaan untuk tetap survive dalam dunia persaingan adalah dengan cara meningkatkan dan mempertahankan customer loyalty. Dengan meningkatkan dan mempertahankan customer loyalty tentunya akan meningkatkan tingkat pembelian konsumen terhadap suatu perusahaan yang akan berdampak terhadap keuntungan suatu perusahaan dan mengurangi biaya pemasaran suatu perusahaan.

Berdasarkan uraian di atas, penting bagi restoran Meradelima untuk mengetahui dimensi yang dapat memicu terjadinya customer loyalty dimana loyalitas merupakan kepuasaan konsumen terhadap kinerja produk atau jasa. 
Berdasarkan hal tersebut dapat dirumuskan pertanyaan seperti berikut:

1. Apakah terdapat pengaruh service quality terhadap customer satisfaction pada konsumen Pizza Hut di Jakarta Selatan.

2. Apakah terdapat pengaruh corporate image terhadap customer satisfaction pada konsumen Restoran Meradelima di Jakarta Selatan.

3. Apakah terdapat pengaruh service quality terhadap customer loyalty pada konsumen Pizza Hut di Jakarta Selatan.

4. Apakah terdapat pengaruh corporate image terhadap customer loyalty pada konsumen Restoran Meradelima di Jakarta Selatan.

5. Apakah terdapat pengaruh customer satisfaction terhadap customer loyalty pada konsumen Restoran Meradelima di Jakarta Selatan.

6. Apakah terdapat pengaruh service quality melalui customer satisfaction terhadap customer loyalty pada konsumen Restoran Meradelima di Jakarta Selatan.

7. Apakah terdapat pengaruh corporate image melalui customer satisfaction terhadap customer loyalty pada konsumen Restoran Meradelima di Jakarta Selatan.

8. Apakah terdapat pengaruh service quality dan corporate image melalui customer satisfaction terhadap customer loyalty pada konsumen Restoran Meradelima di Jakarta Selatan.

\section{KAJIAN TEORI DAN PENGEMBANGAN HIPOTESIS}

Menurut Kotler dan Keller $(2016,156)$ "service quality is totality of features and characteristics of a product or service that bear on its ability to satisfy stated or implied needs." Maksudnya adalah karakteristik dari produk atau jasa yang bertujuan untuk memuaskan kebutuhan yang dinyatakan atau tersirat.

Kotler dan Keller $(2016,550)$ menyebutkan coporate image adalah "the set of beliefs, ideas and impression a person holds regarding an corporate." Maksudnya adalah keyakinan, ide dan kesan seseorang mengenai suatu perusahaan.Berdasarkan paparan teori dan temuan penelitian terdahulu, maka dapat dibangun kerangka penelitian sebagai berikut:

Berdasarkan penelitian yang dilakukan peneliti, peneliti menemukan hipotesa sebagai berikut:

$\mathrm{H}_{1}$ : Terdapat pengaruh service quality terhadap customer satisfaction pada konsumen Pizza Hut di Jakarta Selatan.

$\mathrm{H}_{2}$ : Terdapat pengaruh corporate image terhadap customer satisfaction pada konsumen Pizza Hut di Jakarta Selatan.

$\mathrm{H}_{3}$ : Terdapat pengaruh service quality terhadap customer loyalty pada konsumen Pizza Hut di Jakarta Selatan.

$\mathrm{H}_{4}$ : Terdapat pengaruh corporate image terhadap customer loyalty pada konsumen Restoran Meradelima di Jakarta Selatan.

$\mathrm{H}_{5}$ : Terdapat pengaruh customer satisfaction terhadap customer loyalty pada konsumen Restoran Meradelima di Jakarta Selatan.

$\mathrm{H}_{6}$ : Terdapat pengaruh service quality melalui customer satisfaction terhadap customer loyalty pada konsumen Restoran Meradelima di Jakarta Selatan.

$\mathrm{H}_{7}$ : Terdapat pengaruh corporate image melalui customer satisfaction terhadap customer loyalty pada konsumen Restoran Meradelima di Jakarta Selatan.

$\mathrm{H}_{8}$ : Terdapat pengaruh service quality dan corporate image melalui customer satisfaction terhadap customer loyalty pada konsumen Restoran Meradelima di Jakarta Selatan.

\section{METODE PENELITIAN}

Metode yang digunakan dalam penelitian ini adalah penelitian deskriptif dan kausal. Menurut Sekaran dan Bougie $(2013,97)$ penelitian deskriptif adalah "Descriptive studies are 
often designed to collect data that describe the characteristic of persons, event, or situations". Maksudnya adalah penelitian yang menggambarkan karakteristik responden yang contohnya terdiri dari jenis kelamin, usia, dan penghasilan.

Sedangkan teknik pengambilan sampel dalam penelitian ini menggunakan metode purposive sampling. Purposive sampling menurut Sekaran dan Bougie (2013:252) adalah teknik penentuan sampel dengan pertimbangan tertentu dan mempunyai kriteria yang spesifik.

\section{HASIL PENELITIAN DAN PEMBAHASAN}

Untuk uji karakteristik responden, sebanyak 110 responden yang masih aktif belajar di Resto Meradelima. Hasil dari analisis karakteristik responden pada penelitian ini sebagian besar kelamin laki-laki lebih banyak yaitu sebesar 52,7 \%, sedangkan untuk jenis kelamin perempuan sebesar 47,3\%, 26 - 33 tahun berjumlah 36 orang atau sebesar 32,7 \%, pendapatan sebesar > 6.000.000 yang memiliki presentase 59,1\% dengan jumlah 65 orang.

Tabel 2

Hasil Uji-F (Uji Simultan)

ANOVA $^{\mathrm{a}}$

\begin{tabular}{|l|l|r|r|r|r|r|}
\hline \multicolumn{2}{|l|}{ Model } & Sum of Squares & df & Mean Square & F & Sig. \\
\hline \multirow{4}{*}{1} & Regression & 391,217 & 2 & 195,608 & 86,013 &, $000^{\mathrm{b}}$ \\
\cline { 2 - 7 } & Residual & 243,338 & 107 & 2,274 & & \\
\cline { 2 - 8 } & Total & 634,555 & 109 & & & \\
\hline
\end{tabular}

a. Dependent Variable: TOTAL_CS

b. Predictors: (Constant), TOTAL_CI, TOTAL_SQ

Sumber: Hasil Kuesioner yang dioalah dengan program SPSS

Tabel 3

Hasil Uji-F (Uji Simultan)

$\mathrm{ANOVA}^{\mathrm{a}}$

\begin{tabular}{|l|l|r|r|r|r|c|}
\hline \multicolumn{2}{|l|}{ Model } & Sum of Squares & \multicolumn{1}{c|}{ df } & Mean Square & F & \multicolumn{1}{c|}{ Sig. } \\
\hline \multirow{3}{*}{1} & Regression & 89,537 & 3 & 29,864 & 9,985 &, $000^{\mathrm{b}}$ \\
\cline { 2 - 8 } & Residual & 316,827 & 106 & 2,989 & & \\
\cline { 2 - 8 } & Total & 406,364 & 106 & & & \\
\hline
\end{tabular}

a. Dependent Variable: total CL

b. Predictors: (Constant), total CS, total CI, total SQ

Sumber: Hasil Kuesioner yang dioalah dengan program SPSS

Dapat dilihat pada tabel 4.12 yaitu nilai $\operatorname{Sig}=0,000$ dan $\alpha=0,05$. Maka nilai $p$-value (Sig) $<\alpha(0,000<0,05)$. Karena nilai signifikan Service Quality, Corporate Image dan Customer Satisfaction lebih kecil dari nilai $\alpha$, maka penelitian masuk dalam kategori cocok (Goodness of Fit), dan terdapat pengaruh yang signifikan antara variabel Service Quality, Corporate Image, dan Customer Satisfaction terhadap Customer Loyalty.

\section{Tabel 4}

\section{Hasil Uji- t}

Coefficients $^{\mathrm{a}}$

\begin{tabular}{|c|c|c|c|c|c|c|}
\hline \multirow{2}{*}{\multicolumn{2}{|c|}{ Model }} & \multicolumn{2}{|c|}{$\begin{array}{c}\text { Unstandardized } \\
\text { Coefficients }\end{array}$} & $\begin{array}{l}\text { Standardized } \\
\text { Coefficients }\end{array}$ & \multirow[t]{2}{*}{$\mathrm{t}$} & \multirow[t]{2}{*}{ Sig. } \\
\hline & & B & Std. Error & Beta & & \\
\hline \multirow{3}{*}{1} & (Constant) & 4,624 & 1,405 & & 3,290 &, 001 \\
\hline & TOTAL_SQ &, 776 &, 104 &, 783 & 7,458 &, 000 \\
\hline & TOTAL_CI &, 473 & ,198 & ,463 & 4,031 &, 075 \\
\hline
\end{tabular}

a. Dependent Variable: TOTAL_CS 
Tabel 4

Hasil Uji- $t$

Coefficients $^{\mathrm{a}}$

\begin{tabular}{|c|c|c|c|c|c|}
\hline \multirow[t]{2}{*}{ Model } & \multicolumn{2}{|c|}{ Unstandardized Coefficients } & \multirow{2}{*}{$\frac{\text { Standardized Coefficients }}{\text { Beta }}$} & \multirow[t]{2}{*}{$\mathrm{t}$} & \multirow[t]{2}{*}{ Sig. } \\
\hline & B & Std. Error & & & \\
\hline (Constant) & 9,294 & 1,691 & & 5,497 &, 000 \\
\hline TOTAL_SQ &, 032 &, 147 & ,040 & 3,215 &, 003 \\
\hline 1 TOTAL_CI &, 044 &, 112 & 059 & 2,394 &, 015 \\
\hline TOTAL_CS & ,380 &, 111 & 475 & 3,431 & 001 \\
\hline
\end{tabular}

a. Dependent Variable: TOTAL_CL

Berdasarkan tabel diatas maka dapat ditarik kesimpulan sebagai berikut:

H 1. Analisa pengaruh Service Quality terhadap Customer Satisfaction sebesar 0,000 < 0,05. Sehingga dapat disimpulkan bahwa secara langsung terdapat pengaruh signifikan X1 terhadap Y.

H 2. Analisa pengaruh Corporate Image terhadap Customer Satisfaction sebesar 0,075 < 0,05. Sehingga dapat disimpulkan bahwa secara langsung terdapat pengaruh signifikan X2 terhadap Y.

H 3. Analisa pengaruh Service Quality terhadap Customer Loyalty sebesar 0,003 < 0,05. Sehingga dapat disimpulkan bahwa secara langsung terdapat pengaruh signifikan X1 terhadap Z.

H 4. Analisa pengaruh Corporate Image terhadap Customer Loyalty sebesar 0,015<0,05. Sehingga dapat disimpulkan bahwa secara langsung terdapat pengaruh signifikan X2 terhadap Z.

H 5. Analisa pengaruh Customer Satisfaction terhadap Customer Loyalty sebesar 0,000<0,05. Sehingga dapat disimpulkan bahwa secara langsung terdapat pengaruh signifikan $\mathrm{Y}$ terhadap Z.

H 6. Analisa pengaruh Service Quality (X1) melalui Customer Satisfaction (Y) terhadap Customer Loyalty (Z). Diketahui pengaruh langsung yang diberikan Service Quality (X1) terhadap Customer Loyalty (Z) sebesar 0,040, sedangkan pengaruh tidak langsung Service Quality (X1) melalui Customer Satisfaction (Y) terhadap Customer Loyalty (Z) adalah perkalian antara beta Service Quality terhadap Customer Satisfaction dengan nilai beta Customer Satisfaction terhadap Customer Loyalty yaitu 0,783 x 0,475=0,371. Maka pengaruh total yang diberikan Service Quality terhadap Customer Loyalty adalah pengaruh langsung ditambah dengan pengaruh tidak langsung yaitu: 0,040+0,371=0,411. Berdasarkan hasil perhitungan diatas diketahhui bahwa nilai pengaruh langsung sebesar 0,040 dan pengaruh tidak langsung sebesar 0,371 yang berarti bahwa nilai pengaruh tidak langsung lebih besar dibanding dengan nilai pengaruh langsung, hasil ini menunjukkan bahwa secara tidak langsung Service Quality (X1) melalui Customer Satisfaction (Y) mempunyai pengaruh signifikan terhadap Customer Loyalty $(\mathrm{Z})$

H 7. Analisa pengaruh Corporate Image (X2) melalui Customer Satisfaction (Y) terhadap Customer Loyalty (Z). Diketahui pengaruh langsung yang diberikan Corporate Image (X2) terhadap Customer Loyalty (Z) sebesar 0,059, sedangkan pengaruh tidak langsung Corporate Image melalui Customer Satisfaction terhadap Customer Loyalty adalah perkalian antara beta Corporate Image terhadap Customer Satisfaction dengan nilai beta Customer Satisfaction terhadap Customer Loyalty yaitu 0,562 x 0,475 =0,266. Maka pengaruh total yang diberikan Service Quality terhadap Customer Loyalty adalah pengaruh langsung ditambah dengan pengaruh tidak langsung yaitu: 0,059+0,266=0,325. Berdasarkan hasil perhitungan diatas diketahhui bahwa nilai pengaruh langsung sebesar 0,059 dan pengaruh tidak langsung sebesar 0,266 yang berarti bahwa nilai pengaruh tidak langsung lebih besar dibanding dengan nilai pengaruh langsung, hasil ini menunjukkan 
bahwa secara tidak langsung Corporate Image (X2) melalui Customer Satisfaction (Y) mempunyai pengaruh signifikan terhadap Customer Loyalty $(\mathrm{Z})$

H 8. Terdapat pengaruh Service Quality (X1) dan Corporate Image (X2) melalui Customer Satisfaction (Y) secara simultan mempengaruhi Customer Loyalty (Z) dapat diterima.

\section{KESIMPULAN}

Berdasarkan hasil analisa dan pembahasan yang telah dikemukakan pada bab IV, ada beberapa kesimpulan yang diperoleh antara lain :

1. Terdapat pengaruh antara Service Quality $\left(\mathrm{X}_{1}\right)$ terhadap Customer Satisfaction, (Y) pada konsumen Restoran Meradelima di Jakarta Selatan.

2. Terdapat pengaruh antara Corporate Image $\left(\mathrm{X}_{2}\right)$ terhadap Customer Satisfaction (Y) pada konsumen Restoran Meradelima di Jakarta Selatan.

3. Terdapat pengaruh antara Service Quality $\left(\mathrm{X}_{1}\right)$ terhadap Customer Loyalty $(\mathrm{Z})$ pada konsumen Restoran Meradelima di Jakarta Selatan.

4. Terdapat pengaruh antara Corporate Image $\left(\mathrm{X}_{2}\right)$ terhadap Customer Loyalty $(\mathrm{Z})$ pada konsumen Restoran Meradelima di Jakarta Selatan.

5. Terdapat pengaruh antara Customer Satisfaction (Y) terhadap Customer Loyalty (Z) pada konsumen Restoran Meradelima di Jakarta Selatan.

6. Terdapat pengaruh antara Service Quality $\left(\mathrm{X}_{1}\right)$ melalui Customer Satisfaction (Y) terhadap Customer Loyalty (Z) pada konsumen Restoran Meradelima di Jakarta Selatan.

7. Terdapat pengaruh antara Corporate Image (X2) melalui Customer Satisfaction (Y) terhadap Customer Loyalty (Z) pada konsumen Restoran Meradelima di Jakarta Selatan.

8. Terdapat pengaruh antara Service Quality $\left(\mathrm{X}_{1}\right)$ dan Corporate Image (X2) melalui Customer Satisfaction (Y) terhadap Customer Loyalty (Z) pada konsumen Restoran Meradelima di Jakarta Selatan.

\section{SARAN}

1. Restoran Meradelima harus bisa menjaga dan meningkatkan kualitas pelayanan serta citra perusahaan, karena dengan demikian maka akan tercipta kepuasaan pelanggan yang positif. Dengan hal ini Restoran Meradelima dapat menarik calon konsumen yang lebih banyak dan dapat mempertahankan konsumen yang sudah lama atau yang masih menjadi konsumen baru.

2. Restoran Meradelima juga harus dapat menepati janji - janjinya serta menjalankan fungsinya dengan baik agar membuat konsumen yakin dan percaya akan adanya kepuasan di masa depan.

3. Restoran Meradelima harus bisa menjaga dan mempertahankan kepuasan konsumen mereka, serta berusaha untuk meningkatkannya lebih baik lagi agar konsumen tidak ragu dan yakin untuk memilih bersantap di Restoran Meradelima.

\section{DAFTAR PUSTAKA}

Anderson David R., Sweeney Dennis J., Williams Thomas A., Camm Jeffrey D., Cochran James J., (2014). Statistic for Business and Economics. $12^{\text {th }}$ Edition. International Edition.

Aydin, S., \& Özer, G. (2005). The analysis of antecedents of customer loyalty in the Turkish mobile telecommunication market. European Journal of Marketing, 39(7/8), 910-925.

Clow, E. Kenneth, and Donald Baack. (2014). "Integrated Advertising, Promotion, and Marketing Comunication." $4^{\text {th }}$ Edition. Pearson International Edition.

Gujarati, Damodar N. (2009). Basic Econometric. $5^{\text {th }}$ Edition. International Edition. Mc GrawHill International Edition.

Hair, Joseph F. Wiliam C. Black., Barry J. Babin, Rolph E. Anderson., and L. Tatham. 2010. "Multivariate Data Analysis." $7^{\text {th }}$ Editional Pearson Prentice. 
Hunt, C. Shane, and John E. Mello. (2015). “Markting.” McGraw-Hill Education.

Kotler, Phillip, and Kevin Lane Keller. (2016). "Marketing Management". 15eth Edition.Pearson International Edition.

Kotler, Philip, Kevin Lane Keller, Swee Hoon Ang, Chin Tiong Tan, Siew Meng Leong. (2018). "Marketing Management An Asian Perspective." $15^{\text {th }}$ Edition Pearson Education

Kumar, R. K., \& Srivastava, M. (2013). The antecedents of customer loyalty: An empirical investigation in life insurance context. Journal of Competitiveness, 5(2).

Ling, K. C., Mun, Y. W., \& Ling, H. M. (2011). Exploring factors that influence customer loyalty among Generation Y for the fast food industry in Malaysia. African Journal of Business Management, 5(12), 4813.

Lovelock, Christopher, and Johan Wirtz. 2011. "Service Marketing People, Technology Strategy." 7th Edition.Pearson International Edition.

Oliver RL (1999). Whence consumer loyalty?. J. Mark., 63(October): 33- 44.

Rashid, I. M. A., Rani, M. J. A., Yusuf, B. N. M., \& Shaari, M. S. (2015). THE IMPACT OF SERVICE QUALITY AND CUSTOMER SATISFACTION ON CUSTOMER'S LOYALTY: EVIDENCE FROM FAST FOOD RESTAURANT OF MALAYSIA. International Journal of Information, Business and Management, 7(4), 201.

Schiffman, Lean G, and Leslie Lazar Kanuk.2010."Customer Behavior." $10^{\text {th }}$ Edition. Pearson International Edition.

Sekaran, Umar., and Bougie. 2013. "Research Methods for Business: A Skill-Building Approach." $5^{\text {th }}$ Edition. Jhon Wiley \& Sons, Inc.

Semuel, H., \& Wijaya, E. (2010). Corporate Social Responsibility, Purchase Intention dan Corporate Image pada Restoran di Surabaya dari Perspektif Pelanggan. Jurnal Manajemen Pemasaran, 3(1), pp-35.

Sugiyono, Dr., Prof., (2015). Metode Penelitian Manajemen, ALFABETA BANDUNG.

Widarjono, Agus. 2015. “Analisis Multivariat Terapan.” $2^{\text {th }}$ UPP STIM YKPN. 